\title{
Exploratory Analysis of Emergence of Dengue Fever Cases in Delhi, India
}

\author{
Netra Pal Singh
}

Corresponding author: netra.singh@gmail.com

Management Development Institute

Gurgaon, India

\section{About the author}

Netra Pal Singh is a professor of Information Management at Management Development Institute in India. He received his M.Sc. from CCS Meerut University Meerut, India, M.S. from Birla Institute of Technology \& Science, Pilani, India, and Ph.D. from CCS Haryana Agriculture University, Hisar, India. His research experience and interests are telecommunication management, business intelligence, enterprise systems and optimization models. He has published more than eighty articles in national \& international journals and completed fifty consulting assignments for governments and cooperates. 


\section{abstract}

This research paper presents a historical analysis of the unprecedented growth of dengue fever cases in Delhi (the capital city of India) during 2015 with an objective to identify factors responsible for its spread and suggest corrective measures to control the disease. The study was conducted based on secondary data with respect to dengue spread in Delhi from various sources, such as newspapers, published scientific research papers, internet, and news bulletins of the health organizations at the central and state governments in India. Data with respect to Ayurvedic treatment of dengue fever was from the selected employees of a private hospital in Faridabad (State of Haryana, India). As a result, two factors were identified to be responsible for the fast spread of dengue: climatic conditions and the delayed reaction of health organizations to control mosquitoes. Another unique finding in this study was that most patients go for Ayurvedic treatment at hospitals equipped with facilities for allopathy only. This study recommends that health organizations should invest in research about dengue, develop innovative methods for forecasting and reduce the treatment cost. In addition, health organizations must be proactive in educating citizens and controlling the disease.

Keywords:Dengue Fever, Delhi, Treatment Cost, Medical Insurance, Serotypes

\section{Introduction}

Dengue has become a global problem over the years as is evident from statistics. Gupta et al. (2012a) reported that 2.5 billion people live in dengue-risk regions with about 100 million new cases are added each year worldwide. They also mentioned that the cumulative burden of dengue disease had increased in an unprecedented proportion in recent years with a large population at risk. According to Brady et al. (2015), about 3.9 billion people, in 128 countries, are at the risk of being infected with dengue viruses. There is still no specific treatment of dengue fever at the current stage and its fatality rate is less than $1 \%$. It is a well-known fact that four distinct, but closely related serotypes of the virus are causing dengue fever. They are named as DEN-1, DEN-2, DEN-3 and DEN-4 (World Health Organization, 2017). During the year 2015, a large number of dengue fever cases was discovered at different places of India. The national capital state, Delhi had to face an unpredictable number of dengue fever patients.

Dengue appeared in Delhi many years ago. It was reported to occur in Delhi during 1967, 1970, 1982 (Dhar et al., 1999). But the official diagnosis of dengue fever in Delhi was not conducted until 1996. Since then, it became a permanent resident of Delhi. Moreover, the surrounding areas of Delhi are also being infected each year. Many states, where dengue fever cases were not commonly seen before, suffer from its emergence in recent years. In those places, the population density is much higher than in Delhi. Thanks to the political position of Delhi, more resources can be employed for the control of the disease because it is the national capital. But the scenario is totally different in the surrounding areas. News of this epidemic disease in the capital city each year may impact many sectors of the national economy. It has become one of the most challenging missions for the Indian government to prevent dengue fever from spreading. 
Scientists of The National Institute of Malaria Research (NIMR), India and the health officials at the Municipal Corporation of Delhi (MCD) quoted that the climate change was one of the major factors responsible for the prolonged spell of Dengue cases in the capital (Nandi, 2015). Singh (2015) stressed that the unplanned urbanization, which resulted in inadequate water supply in the city, could also be responsible for the repeated outbreaks of dengue fever. In order to meet their need for water, people are storing water in tankers. These tankers are not cleaned as they should be and thus have created breeding spaces for mosquitoes. Nandi (2015) pointed out that every house may have 15-16 containers on average, such as flower vases, and bamboo and bird feeding pots. There are many more reasons for the spread of dengue fever in India, but the lack of serious statistical data has hampered the intervention of the authorities from taking effective measures to prevent the reoccurrence of this disease, as per the reports of NIMR and MCD.

Patients with dengue fever tend to opt for allopathic treatment since most of the famous hospitals are equipped with facilities for this treatment especially in big cities in India. Delhi is not an exception. There are 37 government-owned hospitals in the States of Delhi, but very few well-known hospitals offer homeopathic and Ayurvedic treatment. According to the official data, among these 37 hospitals, one offers Ayurvedic treatment, two offer homeopathic treatment and the remaining 34 hospitals offer allopathic treatment.

However, dengue has had made Ayurvedic treatment very popular among patients in India. Many patients choose to take Ayurvedic treatment while staying at hospitals, where even the allopathic treatment infrastructure is available. The most popular treatment with the patients is goat milk, juice of papaya leaves, juice of Tinospora Cordifolia (Giloy) leaves, juice of tulsi (Ocimum Tenuiflorum) leaves and ginger powder. Some of the medications made of natural ingredients are also available at markets. They are given to the patients of dengue fever their caretakers and family members even after they are admitted to hospitals with professional doctors and nursing staff. Patients would follow the instructions from people they trust rather than the medical staff at hospitals.

The epidemic nature of dengue fever has caused the huge cost to the country each year. But there is no vaccine available to control the occurrence and spread of this disease except eliminating the mosquito breeding sites. In order to offer more evidence for effective control of dengue fever, this paper summarizes the general situation of the dengue fever cases in the state of Delhi, analyzes more reasons responsible for this disease and focuses on possible measures for prevention. This study highlights that the neglect of research and innovation by government health organizations serves as the major cause for its emergence or reemergence. This study makes the following suggestions regarding the desirable actions in the control of dengue fever: (1) to increase the investment in research and innovations about the treatment of this disease; (2) to create exhaustive databases to forecast its spread; (3) to reduce the treatment cost for patients who are not covered by the medical insurance; and (4) to take possible proactive actions to prevent its emergence.

\section{Methodology}

This research note consists of an exploratory analysis of the statistical data of dengue cases in Delhi, a summary of the historical perspective and its unique trend from 1991 onwards. This study is based on 
secondary data collected from different sources including newspapers, published scientific research papers, the internet websites and the news bulletins of health organizations of the government. Furthermore, the author interviewed fifteen employees of the private hospitals in Delhi (India) and Faridabad (India) with respect to the treatment of the dengue fever and its cost. Such first-handed data is basically qualitative in nature but includes some quantitative data as well with respect to the treatment cost. Because these medical employees would rather not discuss the issue regarding the dengue treatment in groups and in public. Therefore, the author held private and individual discussions with them. In addition, the author collected data from more than 30 patients about their expectations in the treatment of dengue fever and the acceptable amount for its cost. Past numerical data are presented in the form of tables to support more meaningful conclusions. These data include the number of dengue fever cases in Delhi as reported by the various organization, the spread of dengue fever in different areas of Delhi, the types of dengue fever in Delhi in each different years, etc.

Based on the analysis of the above data, this study attempts to identify the public concerns related to dengue fever, reveal some of the research and innovation efforts for its control and highlights the challenge of the changing patterns of serotypes and the high cost the patients have to burden.

\section{Exploratory Analysis of the Statistical Data of Dengue Cases in Delhi}

This section presents an exploratory analysis of the statistical data of dengue fever cases as reported in the various areas of Delhi. It is worth mentioning that these data are collected from well-known sources, including data collected both by the official government and private organizations in Delhi. As the capital of the country, Delhi has a connected network of hospitals, which shares data for medical treatment. Therefore, data about the dengue fever cases were available to the public.

\section{Confusing Data of the dengue deaths in Delhi (2010 2015)}

Table 1 Dengue Death in Delhi (2010 2015)

\begin{tabular}{lllllll}
\hline Year & 2010 & 2011 & 2012 & 2013 & 2014 & 2015 \\
\hline MCD data & 8 & 8 & 4 & 6 & 3 & 17 \\
State Government Data & 411 & 104 & 219 & 413 & 74 & NA \\
\hline
\end{tabular}

Source: Jha, 2015

The numbers of the deaths caused by dengue fever in Delhi from 2010 to 2015 are shown as in Table 1. These data were collected from two sources of the state government of Delhi. One is the Municipal Corporation of Delhi (MCD) and the other is the state government of Delhi. It is evident that the data from these two sources do not coincide with each other, which suggests the poor quality of the data. There is a huge difference between the two sets of data provided by the two arms of state government. It is very 
confusing which set of data tells about the true situation. The important issue is that these data are used by health organizations for discussions on how to control the dengue fever. It is an urgent need that government should devise more functional methods for data collection regarding the dengue fever. Without reliable data on hand, no production discussion can be held on how to reduce its emergence. This is a typical case of the serious variation in the reported data about dengue fever cases from different sources within the country.

\section{Corrective data of dengue fever}

It is very difficult for definite figures regarding the dengue fever cases and its deaths. Though different sets of data provide different numbers, the author made an effort to make meaningful explanations about those figures and find out the trend in its occurrence. The data presented in Table 2 is an investigation conducted at Hindu Rao Hospital (HRH), a government-owned hospital with 980 beds in North Delhi, India. It is concluded in this preliminary study that out of the 8,138 samples, 1,600 (19.7\%) were found positive for dengue-specific IgM antibodies. This indicates that some of the patients who visit hospitals with fever are not dengue-infected. Table 2 also shows that there was a decreasing trend in the total number of dengue fever cases at this hospital during 20062010 and the occurrence of this disease is seasonally affected by the terrible climate conditions. The hot and humid weather in Delhi is the major factor causing this disease. The number of death cases decreased during the same period of time. This could be closely related to the effective measures taken by the health department in controlling the breeding of mosquitoes, which largely prevents the deterioration of the disease.

Table 3 and 4 offer information about the emergence of dengue fever during 2010 to 2015. It can be seen from the data that there were dengue fever cases in all months except January in 2015. This, once again, proves that this disease is a seasonal phenomenon, and the hot and humid weather is a major cause. Table 3 shows that dengue fever happens more frequently in the latter half of the year. If the dengue fever cases are large in number in July, then more striking numbers of infected cases will follow in the coming months of the year. This was the case with 2015, too.

Table 5 gives a summary of the data from 2002 to 2015. According to Table 2 and Table 3, it can be inferred that there was a reduction in deaths caused by dengue fever after 2006 in Delhi. The reasons are not clearly reported in the literature. One possible reason could be the climatic conditions. When the hot and humid weather prolonged in the summer of 2015, there was the sudden outbreak of dengue fever in Delhi.

\section{Breaking all Records}

According to TNN (2015b), the figure of the dengue cases and deaths shows unprecedented growth in 2015 (Table 6). But at the end of October 2015, there was a decline in the number of new dengue cases (Table 7). Four reasons were cited by the experts for this decline: (1) declining temperature; (2) intensive fogging; (3) improvement of the public awareness to protect themselves; and (4) proactive role of government agencies. It was further reported that Den-2 (Type-II) and Den-4 (Type-IV) were the predominant virulent strains which led to the outbreak of dengue fever in 2015. 
Table 2 Dengue Fever Cases in Delhi (2006 2010)

\begin{tabular}{cccccc}
\hline Year/Month & 2006 & 2007 & 2008 & 2009 & 2010 \\
\hline January & 0 & 0 & 0 & 0 & 0 \\
February & 0 & 0 & 0 & 0 & 0 \\
March & 0 & 0 & 0 & 0 & 0 \\
April & 0 & 0 & 0 & 0 & 0 \\
May & 0 & 0 & 0 & 0 & 0 \\
June & 0 & 0 & 0 & 0 & 0 \\
July & 6 & 0 & 0 & 0 & 0 \\
August & 20 & 4 & 39 & 6 & 101 \\
September & 182 & 56 & 126 & 8 & 310 \\
October & 497 & 6 & 60 & 31 & 62 \\
November 56 & 0 & 17 & 13 & 0 & \\
December & 0 & 0 & 0 & 0 & 0 \\
Total & 761 & 66 & 242 & 58 & 473 \\
Deaths & 7 & 1 & 1 & 0 & 1 \\
\hline
\end{tabular}

Source: Sharma et al, 2012

\section{Last few Months of Dengue fever in Delhi in 2015}

Table 8 reports the data from September 21, 2015 to October 20, 2015, the very last month of the outbreak of dengue fever in Delhi. It can be seen from the data given in Table 8 that numbers of cases of dengue fever have increased from 3791 on September 21 to 12,531 on October October 20, 2015. This was certainly an alarming situation. Some hospitals, such as Lok Nayak Hospital, reported that $90 \%$ new cases were dengue positive during the above mentioned time. The entire city of Delhi was affected by the disease and the impact of dengue was not limited to a corner. Though the data is not complete but give an idea that the disease put Delhi in a serious situation.

\section{Types of Dengue Viruses Prevalent in Delhi}

As explained above, there are four types of viruses that spread dengue disease in India. These viruses are called type 1 to type 4 or DEN-1 to DEN-4 or DV-1 to DV-4. Type 1 is identified with the classic dengue fever, and Type 3 causes high grade-fever without shock. These two are identified as relatively mild serotypes. The most severe strain is Type 4, which leads to high fever shock. Type 2 causes thrombocytopenia or a drop in platelets, hemorrhagic fever and organ failure, which are also called Dengue Shock Syndrome (DSS) (Chatterjee, $\left.2015^{a}\right)$. 
Table 3 Dengue Fever Cases in Delhi (2010 2015)

\begin{tabular}{ccccccc}
\hline Year/Month & 2010 & 2011 & 2012 & 2013 & 2014 & 2015 \\
\hline January & 0 & 0 & 0 & 2 & 0 & 0 \\
February & 0 & 0 & 0 & 2 & 0 & 3 \\
March & 0 & 1 & 0 & 0 & 2 & 1 \\
April & 0 & 3 & 2 & 3 & 0 & 3 \\
May & 0 & 0 & 0 & 0 & 3 & 4 \\
June & 1 & 2 & 3 & 2 & 0 & 6 \\
July & 51 & 10 & 4 & 11 & 7 & 36 \\
August & 885 & 51 & 4 & 142 & 11 & 778 \\
September & 2360 & 179 & 55 & 1962 & 87 & 6775 \\
October & 2246 & 512 & 951 & 2442 & 318 & 7283 \\
November & 678 & 328 & 1005 & 889 & 444 & 642 \\
December & 38 & 46 & 69 & 119 & 113 & 0 \\
Total & 6259 & 1132 & 2093 & 5574 & 985 & 15531 \\
Deaths & 8 & 5 & 4 & 6 & 3 & 43 \\
\hline
\end{tabular}

Sources: Nandi, 2015; Outlookindia.com, 2015

Table 4 Dengue Fever Cases in Delhi (2010 2015)

\begin{tabular}{ccccccc}
\hline Year & 2010 & 2011 & 2012 & 2013 & 2014 & 2015 \\
\hline Cases & 70 & 25 & 10 & 19 & 22 & 53 \\
\hline
\end{tabular}

Source: Press Trust of India, 2015

Table 5 Dengue Fever Cases and Deaths in Delhi (2002 2015)

\begin{tabular}{cccccccc}
\hline Year & 2002 & 2003 & 2004 & 2005 & 2006 & 2007 & 2008 \\
\hline Dengue Cases & 45 & 2882 & 606 & 1023 & 3366 & 548 & 1312 \\
Dengue Death & 2 & 35 & 3 & 9 & 65 & 1 & 2 \\
\hline \hline Year & 2009 & 2010 & 2011 & 2012 & 2013 & 2014 & 2015 \\
\hline Dengue Cases & 1153 & 6259 & 1131 & 2094 & 5574 & 961 & 3791 \\
Dengue Death & 3 & 8 & 5 & 4 & 6 & 3 & 17 \\
\hline
\end{tabular}

Source: Nandi, 2015 
Table 6 Dengue Fever Cases in Delhi (2010 2015)

\begin{tabular}{ccccccc}
\hline Year & 2010 & 2011 & 2012 & 2013 & 2014 & 2015 \\
\hline Cases & 3555 & 283 & 98 & 2557 & 120 & 7606 \\
Deaths & 6 & 8 & 4 & 6 & 3 & 25 \\
\hline
\end{tabular}

Source: TNN, $2015^{b}$

Table 7 Dengue Fever Cases in Delhi (2010 2015)

\begin{tabular}{cccc}
\hline Month & August 2015 & September 2015 & Mid-October 2015 \\
\hline Dengue Fever Cases & 778 & 6775 & 4925 \\
\hline
\end{tabular}

Source: Perappadan, 2015

Table 8 Reported Dengue Fever Cases in Delhi during 2015

\begin{tabular}{cccc}
\hline Date of Report & Number of Cases & Number of Deaths & Source \\
\hline September 21 & 3,791 & 17 & PTI (2015c) \\
September 26 & 5,471 & 17 & PTI (2015d) \\
September 28 & 5,982 & 17 & Perappadan (2015b) PTI (2015e) \\
October 01 & 5,968 & 25 & IANS (2015a) \\
October 02 & 6,486 & 25 & TNN (2015a) Outlookindia.com (2015) \\
October 03 & 6,400 & 25 & Dutta (2015) \\
October 05 & 7,606 & 25 & UNI (2015) \\
October 05 & 7,605 & 25 & PTI (2015f) \\
October 10 & 9,438 & 30 & TNN (2015c) \\
October 11 & 9,438 & 30 & PTI (2015g) \\
October 12 & 10,683 & 30 & PTI (2015h) \\
October 15 & 12,020 & 32 & TNN (2015d) \\
October 20 & 12,531 & 32 &
\end{tabular}

Source: Perappadan, $2015^{a}$

The data of the serotypes, which were prevalent in the past years in Delhi, is shown as in Table 9. Again, the data demonstrates inconsistency among the various sources. This could be the result of the different methods used by the experts to investigate. Some of the studies mention only the prominent serotypes, but some describe all the serotypes even with minor presence. In sum, all four types of serotypes have been reported to be responsible for the dengue among the Delhi population. It is difficult to report which serotype is the one causing the serious situation. Sometimes two serotypes or a particular combination of two or three 
serotypes may remain active for several years. Anyhow, there is no clear conclusion as to what on earth is the trend of dengue in Delhi. Since the predominant serotypes are changing constantly, it is difficult to make a prediction and take preventive measures. But, one conclusion is drawn by the majority of researchers that DEN-2 and DEN-4 are more deadly than DEN-1and DEN-3. Since the sample numbers are relatively small compared to the large population in Delhi, support from the government is definitely needed for future research on dengue in Delhi in order to reach more persuasive conclusions.

Table 9 Selected Epidemiological Studies about Dengue Viruses in Delhi

\begin{tabular}{|c|c|c|}
\hline Year & Sample & Virus Type \\
\hline 1988 & 21 pediatric patients & Den-2 (Kabra et al, 1992; Gupta et al, 2006) \\
\hline 1996 & 240 children & Den -2 (Kabra et al, 1999) \\
\hline 1997 & 37 adults; 141 adults & Den-1 (Vajpayee, 1999; Kumaria, 2001) \\
\hline 2001 & No description & Den-1 (Kukreti et al, 2009) \\
\hline 2002 & No description & Den- $1,2,3$ ansd 4 (Gupta et al, 2006) \\
\hline Jun-02 & $\begin{array}{l}320 \text { samples collected } \\
\text { at Lok Nayak Hospital, } \\
\text { Delhi }\end{array}$ & Den- $1,2,3$ and 4 (Kumaria, 2001) \\
\hline 2003 & 1820 samples & Den-1, 2, 3 and 4 (Kukreti et al, 2010; Gupta, 2006) \\
\hline 2003 & 162 suspected samples & Den-3 (Dash, et al, 2006) \\
\hline 2004 & 162 suspected samples & Den-3 (Dash, et al, 2006) \\
\hline 2005 & No description & Den-3 (Gupta, et al 2012; Varshney, 2013; Gupta, et al, 2006) \\
\hline 2006 & 69 samples & Den-3 (Chahar et al, 2009) \\
\hline 2007 & No description & Den-2 and 3 (Gupta, et al 2012b; Varshney, 2013) \\
\hline 2008 & 177 cases & Den-1, 2 and 3 (Chakravarti, et al, 2010) (Gupta et al, 2012b) \\
\hline Sep-07 & No description & $\begin{array}{l}\text { Den-1, 2, } 3 \text { and } 4 \text { (with Den-1 the most prevalent } \\
\text { serotypes) (Matlani and Chakravarti, 2011) }\end{array}$ \\
\hline Nov-10 & No description & Den-1 (Chatterjee, 2015a) \\
\hline 2012 & 107 samples & Den-1, 2 and 3 (Sharma, et al, 2014) \\
\hline 2013 & No description & $\begin{array}{l}\text { Den-2 (Chatterjee, 2015a; Varshney, 2013) Den-2 } \\
\text { was predominant but Den-1 and Den-3 were also } \\
\text { present (Afreenl, 2014; Anwar, 2015) }\end{array}$ \\
\hline 2014 & No description & Den-2 and 4 (PTI, 2015b) \\
\hline 2015 & No description & Den-2 and 4 (Chatterjee, 2015b), Den- 2 and Den- 4 (Anwar, 2015) \\
\hline
\end{tabular}

\section{Conclusions}

Based on the analysis data presented above, the following can be concluded regarding the dengue in Delhi: 
(1) The analysis of various statistics with respect to the number of dengue fever cases in Delhi indicates that cases of dengue were diagnosed throughout the year during 2015 and the number of cases increased in an unprecedented way. It used to be a seasonal disease, starting in the month of July and achieving its peak either in the second half of September or first half of October. But in recent years, it tends to affect people's life in Delhi all year round. The undesirable climatic conditions and the delayed reaction of the health organizations in tackling with the breeding of mosquitoes have been reported to be responsible for the disease. The former issue cannot be controlled but the latter problem could be solved through the combined efforts of the government and the local residents.

Educating urban population is an important part of the proactive measures. Individual residents are supposed to quit irresponsible behaviors in their daily life for more efficient water and garbage/waste management. Communities should gather financial contributions for the upkeep of their surroundings. The government should make environment-friendly laws so that citizen can learn to appreciate advantageous values and benefits through the implementation of such regulations and rules. There is a need to integrate penalty rules into the administrative system so that people will pay attention to improve their sanitary conditions and reduce the risk of being infected by the disease.

(2) Research studies reveal that all four types of serotypes are present in most of the years in the dengue spreading in Delhi, though one or two types may appear to be dominant. Since most of the studies were conducted with a small number of samples in different hospitals in Delhi and not on regular basis, longitudinal studies are in urgent need for meaningful conclusions. Such research activities cannot be conducted smoothly without the budget allocation from the national government.

(3) Due to the poor quality of the data collected by different agencies, there is a stumbling block in the efficient and optimal usage of the limited resources available in controlling the dengue fever in Delhi. Official data always tend to minimize the severity of the situation while unofficial agencies tend to report that dengue caused much more people to dies. Non-governmental media even reported a number of dengue fever cases 300 times higher than the official figure (Burke, 2014). According to Bagla (2015), “National Vector Borne Disease Control Programme captures only 0.35 percent of the annual number of clinically diagnosed dengue cases in India” . An effective recording system will help the government to lead to more precise forecasting and better decisions in policymaking.

The government should make efforts to improve the quality of the data. This can be achieved by implementing technologies such as data warehouse, data marts, big data, data mining, data analytics, into the daily work of Ministry of Health in the central government. Automated integration of different types of data (text, numeric etc.) from different sources should be realized and the database is to be updated at regular intervals. This data should be embedded with forecasting models including data of climatic parameters responsible for the spread of disease in given regions.

(4) The government must come out with policies which encourages research and innovations about Dengue. One step in this direction could be the creation of two to three research centers which take serious record each year and make suggestions on the potentially effective treatment of dengue based on accountable data. The research funding should be provided by the government and non-governmental 
institutions. Organizations such as Tata Institute of Fundamental Research (TIFR), AIIMS, may be provided with the fund to find a solution as it is done in the case of Malaria (Iyer, 2015).

In addition, many precautionary measures are been reported by the health organizations but no specific discussions are being held on the effective treatment of dengue fever. The best-known treatment is Ayurvedic treatment, which is not available to the patients in a scientific way. More experiments need to be conducted with respect to the effectiveness of the above-mentioned herbs in treating dengue. Companies should also develop medicines with natural ingredients which cause less side effects and suffering.

(5) There is an urgent need to develop vaccine for dengue fever as early as possible and effective medicine which can cure the disease as well. It is believed by the local residents that many Ayurvedic treatments, such as the leaf of papaya, Giloy (Tinospora Cordifolia) juice, milk of goat, ginger powder, Tulsi (Ocimum Tenuiflorum) leaves etc., are very effective. But up till now, there has no scientific evidence to show their effectiveness. There is an urgent need for doctors and hospitals to verify their utility of such treatment. Moreover, cheaper alternative medicine is to be developed in order to better help those patients suffering from the disease each year.

\section{References}

Afreenl, N., Deeba, F., Naqvi, I., Shareef, M., Ahmed, A., Broor, S. and Parveen, S., 2014. "Molecular Investigation of 2013 Dengue Fever Outbreak from Delhi, India". PLoS Currents, Vol. 102, No. 6. Retrieved on November 10, 2017, from http://www.ncbi.nlm.nih.gov/pmc/articles/PMC4169351.

Anwar, T., 2015. "Delhi: Cases of Dengue Fever Have Touched 1,259 Highest in Five Years". Firstpost. Retrieved on November 15, 2017, from http://www.firstpost.com/delhi/delhi-cases-of-denguefever-have-touched-1259-highest-in-five-years-2426180.html.

Bagla, P., 2015. "Why Dengue Threat Could Be Up to 1,000 Times Bigger Than You Think". The Indian Press. Retrieved on September 25, 2017, from http://indianexpress.com/article/explained/whydengue-threat-could-be-up-to-1000-times-bigger-than-you-think/.

Brady, O. J., Peter W. G., Bhatt, S., Messina, J. P., Brownstein, J. S., Hoen, A.G., Moyes, at el. 2012.

"Refining the Global Spatial Limits of Dengue Virus Transmission by Evidence-Based Consensus". PLoS Neglected Tropical Diseases. Vol. 6, No. 8, pp. 1-15. Retrieved on September 23, 2017 from http://www.ncbi.nlm.nih.gov/pmc/articles/PMC3413714.

Burke, J., 2014. "India Dengue Fever Cases 300 Times Higher Than Officially Reported - study". Theguardian. Retrieved on September 10, 2017 from http://www.theguardian.com/world/2014/oct/07/ india-dengue-fever-300-times-higher-reported-study.

Chahar, H. S., Bharaj, P., Dar, L., Guleria, R., Kabra, S. K. and Broor, S., 2009. "Co-infections with Chikungunya Virus and Dengue Virus in Delhi, India". Emerging Infectious Diseases Journal. Vol. 15, pp. 1077-1080.

Chakravarti, A., Kumar, A. and Matlani, M., 2010. "Displacement of Dengue Virus Type 3 and Type 2 by 
Dengue Virus Type 1 in Delhi during 2008". Indian Journal of Medical Microbiology. Vol. 28, pp. 412-413. Chatterjee, P., 2015 "Dengue Yo-yo: Why Virus Blows Alternately Hot, Cold in Delhi".October 01. The Indian Express. Retrieved on October 15, 2017 from http://indianexpress.com/article/explained/ dengue-yo-yo-why-virus-blows-alternately-hot-cold-in-delhi/.

Chatterjee, P., 2015b. "Dengue Yo-yo: Why Virus Blows Alternately Hot, Cold in Delhi".October 01. The Indian Express. Retrieved on October 15, 2017 from http://indianexpress.com/article/explained/ dengue-yo-yo-why-virus-blows-alternately-hot-cold-in-delhi/.

Dhar, L., Broor, S., Sengupta, S., Xess, I. and Seth, P., 1999. "The First Major Outbreak of Dengue Haemorrhagic Fever in Delhi, India”. Emerging Infectious Diseases Journal. Vol. 5, pp. 589-590.

Dash, P. K, Saxena, P., Abhyankar, A., Bhargava, R. and Jana, A. M., 2006. "Re-emergence of Dengue Virus Type-3 (Subtype-III) in India: Implications for Increased Incidence of DHF \& DSS". Virology Journal. Vol. 3, pp. 55-65.

Dutta, A. N., 2015. "Prime Delhi Hospitals Turn Out to be a Breeding Ground or Dengue". October 03. Retrieved on October 04, 2017 from http://www.dnaindia.com/india/report-prime-delhi-hospitalsturn-out-to-be-a-breeding-ground-or-dengue-2131136.

Gupta, E., Mohan, S., Bajpai, M., Choudhary, A. and Singh, G., 2012 ${ }^{a}$ "Circulation of Dengue Virus-1 (DENV-1) Serotype in Delhi, during 2010-11 after Dengue Virus-3 (DENV-3) Predominance: A Single Centre Hospital-based Study". Journal of Vector Borne Disease. Vol. 49, pp. 82-85.

Gupta, N., Srivastava, S., Amita, J. A. and Chaturvedi, U. C., 2012 . "Dengue in India". Indian Journal of Medical Research. Vol. 136, No. 3, pp. 373-390.

IANS, 2015 . "Eight More Die of Dengue in Delhi, Official Toll 25". October 01. India Medical Times. Retrieved on October 03, 2017 from http://www.indiamedicaltimes.com/2015/10/01/eight-moredengue-deaths-in-delhi-official-toll-25/.

IANS, 2015 . "Dengue Cases Hit 7,606 in Delhi". October 05. Business Standard. Retrieved on October 06, 2017 from http://www. business-standard.com/article/news-ians/dengue-cases-hit-7-606-indelhi-115100500884_1.html.

Iyer, M., 2015. "TIFR Team Comes Up with Potential Malaria Vaccine". The Times of India. New Delhi Edition, October 22, 2015, Page 16. Retrieved on Nov. 30, 2017 from https: //timesofindia.indiatimes.com/city/mumbai/TIFR-scientists-come-up-with-potentialmalaria-vaccine/articleshow/49486429.cms.

Jha, D. N., 2015. "From 29 to 1.2k, Dengue Toll Swings Wildly". The Times of India. New Delhi Edition, September 29, 2015, Page 1. Retrieved on December 20, 2016 from http://www.pressreader.com/ india/the-times-of-india-new-delhi-edition/20150929.

Kukreti, H., Dash, P. K., Parida, M., Chaudhary, A., Saxena, P. and Rautela R. S., 2009. "Phylogenetic Studies Reveal Existence of Multiple Lineages of a Single Genotype of DENV-1 (Genotype III) in India during 1956-2007". Virology Journal, Vol. 6, pp. 1-9.

Kumaria, R., 2001. "Correlation of Disease Spectrum among Four Dengue Serotypes: A Five-year-hospitalbased Study from India”. Brazilian Journal of Infectious Diseases. Vol. 14, pp. 141-146. 
Matlani, M. and Chakravarti, A., 2011. "Changing Trends of Dengue Disease: A Brief Report from a Tertiary Care Hospital in New Delhi". Brazilian Journal of Infectious Diseases. Vol. 15, pp. 184-185.

Nandi, J., 2015. "Delhi: Climate Change to Intensify Dengue Outbreak: Experts". The Times Group, e-paper. Retrieved on October 12, 2017 from http://epaperbeta.timesofindia.com/ Article . aspx?eid=31808\&articlexml=Climate-change-to-intensify-dengue-outbreak-Experts26092015004025.

Outlookindia.com, 2015. "Dengue Crisis: Delhi Govt Notices to 14 Doctors". October 02. Retrieved on October 04, 2017 from https://www.outlookindia.com/newswire/story/dengue-crisis-delhi-govtnotices-to-14-doctors/915383.

Perappadan, B. S., $2015^{a}$ "1,291 Test Positive for Dengue This Week in the Capital". The Hindu. September 29. Retrieved on October 03, 2017 from http://www.thehindu.com/news/cities/Delhi/1291-testpositive-for-dengue-this-week-in-new-delhi/article7701212.ece.

Perappadan, B. S., 2015 . "Fogging is Ineffective in Controlling Dengue, Says CSE". The Hindu. October 21. Retrieved on October 21, 2017 from http://www.thehindu.com/todays-paper/tp-national/tpotherstates/fogging-is-ineffective-in-controlling-dengue-says-cse/article7785985 . ece.

Press Trust of India (PTI), 2015 . "Over 50 Dengue Cases in Delhi Till July 2015; Highest in 5 Years". News18.com. August 04. Retrieved on October 18, 2017 from http://www.news18.com/news/india/ over-50-dengue-cases-in-delhi-till-july-2015-highest-in-5-years-1029782 .html.

Press Trust of India (PTI), 2015 . "AIIMS Identifies 'Deadly' Dengue Serotypes Virus Circulating in Delhi". ZEENEWS. September 05. Retrieved on October 10, 2017 from http: //zeenews. india.com/news/health/health-news/deadly-dengue-serotypes-circulating-indelhi-this-year-aiims_1667401.html.

Press Trust of India (PTI), 2015c. "Dengue Outbreak: 1919 Fresh Cases in 1 Week; Total Nearly 3,800". NDTV. September 21. Retrieved on October 18, 2017 from http://www.ndtv. com/delhi-news/dengueoutbreak-1919-fresh-cases-in-1-week-total-nearly-3-800-1220007.

Press Trust of India (PTI), 2015 . "1680 Fresh Dengue Cases in a Week, Total Patients Affected Nears 5500 in Delhi". NDTV. September 25. Retrieved on October 18, 2017 from http://www.ndtv.com/delhi-news/1680-fresh-dengue-cases-in-a-week-total-patientsaffected-nears-5500-in-delhi-1223005.

Press Trust of India (PTI), 2015 . "5,151 Dengue Cases in Delhi in Current Month". The Economic Times. September 28. Retrieved on October 18, 2017 from http://articles.economictimes. indiatimes.com/ 2015-09-28/news/66958036_1_dengue-south-delhi-municipal-corporation-cases.

Press Trust of India (PTI), 2015 . "3 More Dengue Deaths Reported in Delhi, Toll Rises to 41". The Times of India. October 10. Retrieved on October 11, 2017 from http://timesofindia.indiatimes. com/city/delhi/3-more-dengue-deaths-reported-in-Delhi-toll-rises-to-41/articleshow/ $49302450 . \mathrm{cms}$.

Press Trust of India (PTI), 2015 . "3,077 Fresh Dengue Cases in Last 1 week; Total Crosses 10K-mark". The Hindu. October 12. Retrieved on October 18, 2017 from http://www.thehindu.com/news/cities/ 
Delhi/3077-fresh-dengue-cases-in-last-1-week-total-crosses-10kmark/article7753616. ece?utm_source=RSS_Feed\&utm_medium=RSS\&utm_campaign=RSS_Syndication.

Press Trust of India (PTI), 2015 . "Delhi Faces Worst Dengue Outbreak since 1996, Over 12,000 Cases Reported". NDTV. October 15. Retrieved on October 18, 2017 from http://www.ndtv. com/delhi-news/ delhi-faces-worst-dengue-outbreak-since-1996-over-12-000-cases-reported-1232700.

Sharma, P., Mittal, V., Chhabra, M., Singh, P., Bhattacharya, D., Kumar, R., Ram, H., Kumar, S., Chauhan, L. S. and Rai, A., 2014. "Dominance Shift of DENV-1 towards Re-Emergence and CoDominant Circulation of DENV-2 \& DENV-3 during Post- Monsoon Period of 2012 in Delhi, India". Journal of Virology and Retrovirology. Vol. 1, No. 1, pp.104-108.

Sharma, Y., Kaur, M., Singh, S., Pant, L., Kudesia, M., and Jain, S., 2012. "Seroprevalence and Trend of Dengue Fever Cases Admitted to a Government Hospital, Delhi - 5 Years Study (2006-10): A Look in to Age Shift". International Journal of Preventive Medicine. Vol. 3, No. 8, pp. 537-543.

Singh, N. P., 2015. "Analysis of Spread of Dengue Fever Cases in India, 2015". Unpublished Research Paper. TNN, 2015a . "Eight More Deaths, City's Dengue Toll Touches 25". The Times of India. October 02. The Times of India, New Delhi Edition, page 8. Retrieved on Nov. 30, 2017 from https://timesofindia.indiatimes.com/city/delhi/Eight-more-deaths-Delhis-dengue-tolltouches-25/articleshow/49188685.cms.

TNN, 2015". "In 2 Weeks, Dengue Outbreak Ebbs in City". The Times of India, October 06. Retrieved on November 01 from https://timesofindia.indiatimes.com/city/delhi/In-2-weeks-dengueoutbreak-ebbs-in-city/articleshow/49234860.cms.

TNN, 2015c. "Dengue Claims SHO, Two Others; Unofficial Toll at 41". Slideshare, October 11. Retrieved on October 20, 2017 from https://www.slideshare.net/parveenkumarchadha3/dengue-claims-shotwo-others.

TNN, 2015 . "Instances of Dengue Likely to Fall after Dussehra". The Times of India. October 20. Retrieved on October 21, 2017 from http://timesofindia.indiatimes.com/city/delhi/Instances-ofdengue-likely-to-fall-after-Dussehra/articleshow/49459228.cms.

Vajpayee, M., Mohan, K. K., Wali, J. P., Dar, L., Seth, P. and Broor, S., 1999. "Dengue Virus Infection during Post-epidemic Period in Delhi, India". Southeast Asian Journal of Tropical Medicine and Public Health. Vol. 30, pp. 507-510.

Varshney, V., 2013. "Dengue Grips Delhi: Virus Strain Circulating This Year More Deadly". Down to Earth. October 8. Retrieved on October 15, 2017 from http://www. downtoearth.org.in/news/dengue-gripsdelhi-virus-strain-circulating-this-year-more-deadly-42385. 